\title{
The Danish National Database for Obstructive Sleep Apnea
}

This article was published in the following Dove Press journal:

Clinical Epidemiology

25 October 2016

Number of times this article has been viewed

\section{Poul Jørgen Jennum' \\ Preben Larsen ${ }^{2}$ \\ Charlotte Cerqueira ${ }^{3}$ \\ Thor Schmidt ${ }^{4}$ \\ Philip Tønnesen' \\ 'Department of Clinical}

Neurophysiology, Faculty of Health Sciences, Danish Center for Sleep

Medicine, University of Copenhagen, Rigshospitalet, Copenhagen, ${ }^{2}$ Section of Respiratory Disease, Medical Department, Fredericia Hospital, Fredericia, ${ }^{3}$ Registry Support Centre (East) - Epidemiology and Biostatistics, Research Centre for Prevention and Health, ${ }^{4}$ Registry Support Centre (East) - Clinical Quality Improvement and Health Informatics, Capital Region of Denmark, Copenhagen, Denmark
Correspondence: Poul Jørgen Jennum Department of Clinical Neurophysiology, Faculty of Health Sciences, Danish Center for Sleep Medicine, University of Copenhagen, Rigshospitalet, Nordre Ringvej 57, DK-2600 Glostrup, Copenhagen, Denmark

Tel +45 38632512

Email poul.joergen.jennum@regionh.dk
Aim: The aim of the Danish National Database for Obstructive Sleep Apnea (NDOSA) was to evaluate the clinical quality (diagnostic, treatment, and management) for obstructive sleep apnea and obesity hypoventilation syndrome in Denmark using a real-time national database reporting to the Danish National Patient Registry.

Study population: All patients diagnosed with obstructive sleep apnea or obesity hypoventilation syndrome at public and private in- and out-hospital departments in Denmark were included.

Main variables: The NDOSA contains information about baseline characteristics, comorbidity, diagnostic procedures conducted, treatment (continuous positive airway pressure and similar treatments, surgery, mandibular advancement devices, etc) complications, and treatment status.

Descriptive data: Yearly report with indicators for diagnostic procedures, treatment, and follow-up comparing different departments was involved in the management of sleep apnea in Denmark for the purpose of quality improvement.

Conclusion: The NDOSA has proven to be a real-time national database using diagnostic and treatment procedures reported to the Danish National Patient Registry.

Keywords: obstructive sleep apnea, obesity hypoventilation syndrome, quality of care, clinical registry

\section{Introduction}

Obstructive sleep apnea (OSA) and obesity hypoventilation syndrome (OHS) are severe sleep-related breathing disorders that in total affect $>5 \%$ of the adult population. Furthermore, OSA also affects children. These disorders are associated with significant morbidities, mortality, and consequently significant societal burden. ${ }^{1-4}$ The Danish National Database for OSA (NDOSA) was initiated in 2009 for the monitoring of management of OSA, diagnostic and treatment procedures, and follow-up to create a nationwide database for quality monitoring and research. More than 50,000 children and adult patients are included in the Danish National Patient Registry. Since the start of quality database in $2009, \sim 8,000$ new patients per year have been included in the NDOSA. During its first year of existence, the quality indicators have increased overall. Diagnostic modalities include polysomnography, partial polygraphy (cardiorespiratory monitoring), and oximetry. Treatment modalities include positive airway pressure (PAP) using all modalities: fixed pressure; auto-adjusted, bilevel, and adaptive PAP; surgical procedures; and other procedures. submit your manuscript | www.dovepress.com Dovepress

http://dx.doi.org/10.2|477/CLEP.S|01969
Clinical Epidemiology 2016:8 573-576 (Thematic series on clinical quality databases in Denmark) $\mathbf{5 7 3}$ (c) (1) (5) 2016 Jennum et al. This work is published and licensed by Dove Medical Press Limited. The full terms of this license are available at https://www.dovepress.com/terms. (c) ${ }_{\mathrm{BY}} \mathrm{NC}$ php and incorporate the Creative Commons Attribution - Non Commercial (unported, v3.0) License (http://(creativecommons.org/licenses/by-n/3.0/). By accessing the work you hereby accept the Terms. Non-commercial uses of the work are permitted without any further permission from Dove Medical Press Limited, provided the work is properly attributed. For permission for commercial use of this work, please see paragraphs 4.2 and 5 of our Terms (https://www.dovepress.com/terms.php). 


\section{Aim of database}

The main aim of the NDOSA was to improve the quality of procedures and care for patients undergoing diagnosis and treatment procedures for OSA in Denmark. In addition, we included patients with a diagnosis of OHS - a more severe form of sleep-disordered breathing associated with severe overweight. By describing variation in clinical practice across the country, the aim was to stimulate quality improvement initiatives to standardize excellence in practice and thus improve outcomes. The NDOSA aims to monitor and support the implementation of evidence-based treatment and care for patients undergoing diagnostic and treatment procedures for sleep-disordered breathing.

\section{Study population}

The NDOSA includes data on all diagnostic procedures from all public and private hospital departments (eg, pulmonary, ear-nose-throat, neurologic) evaluating OSA in Denmark. All data including diagnostic and treatment procedures in the NDOSA are extracted from the Danish National Patient Registry. All Danes hold a unique personal identification number (Central Person Registry number), allowing accurate linkage between health registers and other nationwide administrative registers on an individual level. NDOSA is approved as a clinical quality database by the Danish Health Authority and hospitals and clinics are thus required to report details of all treated patients to the database. Patient consent is not required for entry of data in NDOSA, because according to Danish law, approved clinical quality databases are exempt from the requirement of obtaining patients' consent to collect relevant data. Patient consent is therefore not required for entry of data in the Danish clinical registries.

\section{Main variables}

The variables recorded in the NDOSA are basic patient characteristics, comorbidity, indication for the procedure, the diagnostic tests (polysomnography, partial polygraphy, oximetry) and treatments (PAP and surgical or no treatment), pretreatment apnea severity, treatment compliance, effect of treatment (change in apnea severity, sleepiness), and waiting time.

Registration in the NDOSA is mandatory for all procedures performed in public and private Danish hospitals. As the data registration is obligatory for some of the indicators, the completeness is $100 \%$; however, for one indicator that is not obligatory, the completeness is $97 \%$.

The key outcome data are quality measures, morbidities, mortality, and use of health care (Table 1).
Table I Quality indicators for the Danish NDOSA

\begin{tabular}{|c|c|}
\hline Indicator & \\
\hline I & $\begin{array}{l}\text { Diagnostic method: Which diagnostic method is used } \\
\text { (polysomnography, partial polygraphy, oximetry)? }\end{array}$ \\
\hline 2 & $\begin{array}{l}\text { Treatment with (fixed, continuous, bilevel, adaptive) } \\
\text { positive airway pressure, surgery (eg, uvulopalatophar- } \\
\text { yngoplasty and adenotonsillectomy), oral devices, etc }\end{array}$ \\
\hline 3 & $\begin{array}{l}\text { Treatment with (fixed, continuous, bilevel, adaptive) } \\
\text { positive airway pressure }\end{array}$ \\
\hline 4 & $\begin{array}{l}\text { Patients obtaining good (continuous, bilevel, adaptive) } \\
\text { positive airway pressure compliance (defined as a number } \\
\text { of patients with the use of positive pressure treatment } \\
>4 \text { hours) }\end{array}$ \\
\hline 5 & $\begin{array}{l}\text { Change in apnea severity index from the time of diagnosis } \\
\text { to after treatment }\end{array}$ \\
\hline 6 & $\begin{array}{l}\text { Change in patients symptoms from the time of diagnosis } \\
\text { to after treatment }\end{array}$ \\
\hline 7 & $\begin{array}{l}\text { Control visit of (fixed, continuous, bilevel, adaptive) } \\
\text { positive airway pressure, number of patients at } \\
\text { follow-up }\end{array}$ \\
\hline 8 & Control visit after surgical procedure \\
\hline 9 & $\begin{array}{l}\text { Number of patients undergoing diagnostic procedure } \\
<4 \text { weeks after primary referral to diagnostic department }\end{array}$ \\
\hline
\end{tabular}

Abbreviation: NDOSA, National Database for Obstructive Sleep Apnea.

\section{Follow-up}

Audit is essential for the maintenance of good clinical practice for sleep apnea.

The reported results are critically evaluated at annual meetings with the aim of improving the database content. In the case of outlier results (positive as well as negative), local audit is planned, performed, and published in the final annual report.

Periodic assessments of the quality indicators are published on a monthly basis in the regional information systems. Each department has access to their own results, both to ensure real-time registration and the opportunity to make usage of own results for the further development and quality assurance in the units, respectively. These results are of interest to clinicians in this area and a useful guide for health care administrative workers and managers to help allocate maximum value for the limited resources available.

Based on the register data, it has been shown that the quality regarding diagnostic and treatment procedures as well as follow-up percentage has improved overall (Figure 1). For five indicators, an improvement was observed; for two indicators, a decrease was found; and two indicators were unchanged from 2012 to 2014 . However, the mean increase was only $2.7 \%$ with a range from $-10 \%$ to $+8 \%$ in the actual values. 




Figure I Results for key quality indicators for the Danish NDOSA from 2012 to 2014.

Abbreviations: AHI, apnea-hypopnea index; CPAP, continuous positive airway pressure; NDOSA, National Database for Obstructive Sleep Apnea; PSG, polysomnography.

\section{Examples of research}

Based on the available data from the National Patient Register/NDOSA combined with other national databases, a number of studies have been conducted. These studies suggest that OSA/OHS is associated with significant societal burden in terms of direct and indirect costs and consequently societal costs, ${ }^{1,2}$ as well as an increased morbidity and mortality in children ${ }^{3}$ and adults when compared with healthy controls. $^{4}$

\section{Administrative issues and funding}

The NDOSA was started after a pretest period from 2007 to 2009 to develop data extraction from the National Patient Register. The main problem experienced has been to transform an administrative database to a medical longitudinal database. The first local initiative, by a group of medical doctors, was taken in 2007. In 2009, the NDOSA was a nationwide register.

NDOSA is part of the Danish Clinical Registries a national improvement program and thus funded by the Danish Regions.

\section{Conclusion}

The NDOSA is monitoring all procedures in patients with OSA and OHS in Denmark. It contains information about baseline characteristics, comorbidity, procedures conducted, complications, medical treatment, and follow-up data. Due to these data, we have obtained a national uniform monitoring of the diagnostic and treatment quality in this area.

\section{Acknowledgments}

This paper was funded by the Program for Clinical Research Infrastructure established by the Lundbeck Foundation and the Novo Nordisk Foundation and administered by the Danish Regions. The NDOSA is only possible due to the continued efforts and contributions in the collection of data from the staff of the hospital departments caring for patients with OSA/OHS.

\section{Disclosure}

The authors report no conflicts of interest in this work.

\section{References}

1. Jennum P, Ibsen R, Kjellberg J. Social consequences of sleep disordered breathing on patients and their partners: a controlled national study. Eur Respir J. 2014;43:134-144.

2. Jennum P, Kjellberg J. Health, social and economical consequences of sleep-disordered breathing: a controlled national study. Thorax. 2011;66:560-566

3. Jennum P, Ibsen R, Kjellberg J. Morbidity and mortality in children with obstructive sleep apnoea: a controlled national study. Thorax. 2013;68:949-954.

4. Jennum P, Ibsen R, Kjellberg J. Morbidity prior to a diagnosis of sleepdisordered breathing: a controlled national study. J Clin Sleep Med. 2013;9:103-108. 


\section{Publish your work in this journal}

Clinical Epidemiology is an international, peer-reviewed, open access, online journal focusing on disease and drug epidemiology, identification of risk factors and screening procedures to develop optimal preventative initiatives and programs. Specific topics include: diagnosis, prognosis, treatment, screening, prevention, risk factor modification,

Submit your manuscript here: http://www.dovepress.com/clinical-epidemiology-journal systematic reviews, risk \& safety of medical interventions, epidemiology \& biostatistical methods, and evaluation of guidelines, translational medicine, health policies \& economic evaluations. The manuscript management system is completely online and includes a very quick and fair peer-review system, which is all easy to use. 